\title{
The Relationship between Organizational Learning and Staff Empowerment in Hospital: A Correlational Study in Iran
}

\author{
Jamil Sadeghifar ${ }^{1,2}$, Frouzan Ashrafnejad ${ }^{3}$, Seyed Masood Mousavi ${ }^{4}$, Ali Beigi Nasiri ${ }^{5}$, Ghasem Rajabi \\ Vasokolaei $^{6,7}$, Keyvan Nasrollah Zadeh ${ }^{7}$, Heshmatolah Asadi ${ }^{8}$, Mohammad Saeid Abdinasab ${ }^{7}$, Saman \\ Ghasempour $^{7}$, Mansour Hajiesmaeili ${ }^{7}$, Mostafa Beigi Nasiri ${ }^{9}$ \& Meisam Mosavi ${ }^{10,11}$ \\ ${ }^{1}$ Health Management and Economics Research Center, Iran University of Medical Sciences, Tehran, Iran \\ ${ }^{2}$ Department of Health Education, School of Public Health, Ilam University of Medical Sciences, Ilam, Iran \\ ${ }^{3}$ Iranian Petroleum Industry, ICT \& Health Economics Research Center, Tehran, Iran \\ ${ }^{4}$ Hospital Management Research Center, Iran University of Medical Sciences, Tehran, Iran \\ ${ }^{5}$ Jawaharlal Nehru Technological University, Hyderabad, India \\ ${ }^{6}$ Research Center for Health Services Management, Institute for Futures Studies in Health, Kerman University \\ of Medical Sciences, Kerman, Iran \\ ${ }^{7}$ Department of Health Care Management, School of Allied Medical Sciences, Tehran University of Medical \\ Sciences, Tehran, Iran \\ ${ }^{8}$ Department of Health Management and Economics, School of Public Health, Tehran University of Medical \\ Sciences, Tehran, Iran \\ ${ }^{9}$ Business Management in Finance Branch, Shahid Chamran University, Ahvaz, Iran \\ ${ }^{10}$ Research Center for Modeling in Health, Institute for Futures Studies in Health, Kerman University of Medical \\ Sciences, Kerman, Iran \\ ${ }^{11}$ Students' Scientific Research Center, School of Public Health, Tehran University of Medical Sciences, Tehran, \\ Iran
}

Correspondence: Meisam Mosavi, Research Center for Modeling in Health, Institute for Futures Studies in Health, Kerman University of Medical Sciences, Kerman, Iran. E-mail: m-mousavi@razi.tums.ac.ir

Received: January 19, 2014 Accepted: June 26, 2014 Online Published: July 24, 2014

doi:10.5539/ass.v10n16p27 URL: http://dx.doi.org/10.5539/ass.v10n16p27

\begin{abstract}
One of the newest and most effective strategies to empower staff is building the infrastructure and platform for strengthening organizational learning. This study has conducted about the relationship between organizational learning and staff empowerment. This correlational study was conducted among the staff of a Children's Hospital affiliated to Tehran University of Medical Sciences, Iran in 2012. Numbers of 145 staff in this hospital has selected and enrolled by simple random sampling. The data collection tools were tow questionnaires for organizational learning and staff empowerment which approved their validities and reliabilities. Finally, collected data were analyzed by Spearman correlation test. Among the dimensions of organizational learning, knowledge transfer and integration with 3.47 and system perspective with 3.16 obtained highest and lowest scores respectively. Generally, overall rating of organizational learning and the staff empowerment variables were determined $3.25 \pm 0.71$ and $3.74 \pm 0.59$ respectively. Between the four dimensions of organizational learning (managerial commitment, system perspective, openness and experimentation, knowledge transfer and integration) and staff empowerment, was observed a significant correlation. According to the findings, the current situation of organizational learning and staff empowerment in studied hospital is relatively acceptable. It recommended that hospital systems can improve staff empowerment by developing organizational learning environment, creating experience and knowledge exchange platforms, using material incentives and specially focusing on the intrinsic motivation.
\end{abstract}

Keywords: organizational learning, empowerment, hospital, Iran 


\section{Introduction}

In today's competitive era, classic organizations should have appropriate flexibility to have a favorable response to the continuous changes (Hornstein, 2006; Jerez-Gomez, Céspedes-Lorente, \& Valle-Cabrera, 2005). According to importance role of right decision making on the quality of clinical care in recent years, organizational learning and knowledge management has been carefully regarded (Otala, 2000). Organizational learning is considered as a source of distinction between organizations and a basis for competition (Paajanen, 2012). Marquardt indicated that in addition to financial measures, organizations performance is evaluated as intangible assets, intellectual capital and knowledge-based assets (Marquardt, 1996). Therefore, having knowledge and updated information for an organization such as a hospital, in accordance with breadth and diversity of its activities has become a fundamental necessity (Abeysekera, 2006).

The hospital environment is one of the most engaging work environments, including the interactions between nurses and patients, nurses and doctors, and doctors and patients is that all these interactions can lead to human resource learning and development (Jerez-Gomez et al., 2005). In addition to its primary aim of providing and health promotion, hospitals are kind of a learning organization because they are constantly interacting with their environment in order to generate new knowledge, and they propound the new knowledge in communication networks to help others to take advantage of it (Bahramian, 2005).

Organizational learning is a dynamic process which enables organizations to quickly adapt to changing. This process results in the production of behavior and new skills and it is the main way of working knowledge and improving the efficiency of the organization. Therefore, a successful organization must be dynamic in learning (Zhang, Tian, \& Qi, 2006). The term of organizational learning apparently refers to the individual learning. While, this concept actually refers to learning at the group level because individual learning is gained through reading, interview, knowledge, experience, practice and develop effective mental models. But, organizational learning occurs when the group is trying to learn, interact and to share his knowledge to other members so that combined capacity of the group has increased, and members gain the ability of understanding and effective action (Jerez-Gomez et al., 2005).

There are several models for the study of organizational learning; one of the popular models in this field is Gomez et al. model. This model is based on four dimensions of organizational learning; First dimension is managerial commitment that refers to the production of knowledge and organizational culture as an underlying activity, Because of the key to gain long-term outcomes in organization is organizational learning. Management should ensure that the concept is understood by staff and providing the basis for removal beliefs that are destructive to provide organizational learning (García-Morales, Lloréns-Montes, \& Verdú-Jover, 2007). Second dimension refers to have a clear system perspective for all staff toward organizational objectives which are expressed as the key to the development of organizational goals. The organization should be considered as a system composed of different sectors to work collaboratively together. Organizational attitude as a system implicitly caused to identify the communication in organization that leads to development of a shared mental model, Because of organizational learning uses knowledge, understanding and common principles (García-Morales et al., 2007). Usually, new ideas in intra-organizational and extra- organizational are given in the open environment. This dimension is necessary aspect for creative learning. The ability of creativity, learning from the mistakes of others and support of controlled risks are enhanced by creating experimenting culture that refers to the importance of third dimension of organizational learning that is openness and experimentation (Nikbakht, Siadat, Hoveida, \& Moghadam, 2010). Fourth and the last and most important aspect are the knowledge transfer and integration. Knowledge management is the process of creating, recording, refining, distribution and use of knowledge. These five factors of knowledge management in an organization provide the basis for training, re-training and feedback (Nasr Esfehani, 2007).

On the other hand, in regard with the importance of organizational efficiency principle by using staff empowerment therefore, this concept can provide the basis of creating the objective in a healthy environment (Holsapple, 2003). Organizational empowerment is equal to staff empowerment. Namely, the organization should help them to strengthen their self-confidence and overcome the sense of powerlessness and helplessness; they should be motivated to do activities. On empowerment, employees get self-determination, freedom and more decision making responsibility (Gagné \& Deci, 2005). The main feature of empowerment is aligning individual and organizational goals; some of the managers define staff empowerment as another form of decentralization which involves delegating decision making authority to subordinates that leads to staff participation in the act of management (Jerez-Gomez et al., 2005).

According to the importance of organizational learning and staff empowerment and because the simultaneous 
study of these two components has not been performed at hospital, this study with the purpose of determining the relationship between organizational learning and staff empowerment has been done in a Children's Hospital affiliated to Tehran University of Medical Sciences. The results of this study can determine the components of organizational learning and provide strategies to strengthen them, it can help the organization to make required infrastructure in order to staff empowerment.

\section{Methods}

\subsection{Sample}

This correlational study was conducted among the staff of a Children's Hospital affiliated to Tehran University of Medical Sciences, Iran in 2012. The target population was the staff working in this hospital. Numbers of 145 staff were selected based on simple random sampling.

\subsection{Data Collection}

Data collected by two standard questionnaires, one of them was organizational learning questionnaire consists of 16 questions in four dimensions: managerial commitment (5 questions), system perspective (3 questions), openness and experimentation (4 questions), knowledge transfer and integration (4 questions). The other questionnaire consist of 20 questions were about staff empowerment. The reliability of the questionnaires was done (Aghdasi \& Befruei, 2009) by using Cronbach's alpha in similar studies in which obtained values for Organizational Learning Inventory and staff empowerment are 0.7 and 0.93 respectively. In addition, validity content was used in order to verify the validity. All the above scales utilized a 1-5 (from strongly disagree to strongly agree) response set. Individual scores were calculated by computing scale averages for each dimension.

The participants were visited by the researchers at their work place who handed to them the questionnaires. The researcher visited participants and collected questionnaires by hand, after one week.

\subsection{Data Analysis}

Analysis of collected data was performed by Statistical Package for the Social Sciences (SPSS) software, the version 18. Spearman correlation test was used to assess the correlation between organizational learning and staff empowerment. The meaningfulness level is considered less than 0.05 in all tests.

\subsection{Ethical Issues}

According to the type of study, the researchers do not gain any formal ethical approval from the studied University's Research Ethics Committee. Normally, questionnaires need not a written consent form. So, the participants consented verbally. The names of the respondents were not recorded on the questionnaire, thus rendering the data anonymous

\section{Results}

Among 145 distributed questionnaires, the number 97 questionnaires were completed and returned (Response Rate $=66.9 \%$ ). Administrative-support sector had the highest occupational group of the sample personnel $(60.7 \%)$ and employment status $43.5 \%$ of them was official. The highest frequency of sexuality was related to female $(55.3 \%)$, and highest frequency of age was between $30-50$ years $(70.4 \%)$. Work experience of $59.4 \%$ of staff was over 10 years and the majority of staff had bachelor degree (44.8\%) (Table 1).

Table 1. Distribution of personnel in terms of demographic characteristics

\begin{tabular}{llll}
\hline Variable & & Frequency & Percent \\
\hline \multirow{2}{*}{ Sex } & Male & 43 & 44.7 \\
& Female & 54 & 55.3 \\
Age & Lower than 30 & 26 & 27.3 \\
& Between 30-50 & 68 & 70.4 \\
& Higher than 50 & 3 & 2.3 \\
Educational degree & Diploma and lower & 39 & 40.6 \\
& Technician & 8 & 8.3 \\
Work experience rate & Bachelor & 44 & 44.8 \\
& Master & 6 & 6.3 \\
& Lower than 5 years & 24 & 25.3 \\
\hline
\end{tabular}




\begin{tabular}{llll}
\hline Variable & & Frequency & Percent \\
\hline & 5-10 years & 15 & 15.3 \\
& 10-15 years & 24 & 25.3 \\
15-20 years & 24 & 25.3 \\
& Higher than 20 years & 9 & 8.8 \\
Employment Status & Official & 42 & 43.5 \\
& Contractual & 21 & 21.7 \\
& Project/conventional & 19 & 19.6 \\
Occupational group & Other & 15 & 15.2 \\
& Nursing & 20 & 20.2 \\
& Para clinical & 18 & 19.1 \\
& Administrative-Support & 59 & 60.7 \\
\hline
\end{tabular}

The average of organizational learning was 3.25 , and the staff empowerment component was 3.74. The knowledge transfer and integration dimension obtained the highest average (3.74) in the organizational learning component (Table 2).

Table 2. Mean and standard deviation components of organizational learning and staff empowerment

\begin{tabular}{llllll}
\hline Components & Dimensions & Average & \multicolumn{3}{l}{ SD } \\
\hline \multirow{4}{*}{ Organizational learning } & Managerial commitment & 3.20 & & 0.89 & \\
& System perspective & 3.16 & \multirow{2}{*}{3.25} & 0.87 & 0.71 \\
& Openness and experimentation & 3.18 & & 0.87 & \\
\cline { 2 - 6 } Staff empowerment & Knowledge transfer and integration & 3.47 & & 0.79 & \\
\cline { 2 - 6 } & & 3.74 & & 0.59 & \\
\hline
\end{tabular}

Spearman test was used to assess the correlation between the two factors of organizational learning and staff empowerment in which the Spearman correlation coefficient between these two components were 0.627 with a significant correlation $\mathrm{p}=0.003$ it was observed a significant correlation among all aspects of organizational learning and staff empowerment $(\mathrm{p}<0.05)$ (Table 3$)$.

Table 3. Results of Spearman's test between the dimensions of organizational learning components and the staff empowerment

\begin{tabular}{llll}
\hline Components & & Empowerment & \\
& & Correlation Coefficient & P-Value \\
\hline \multirow{4}{*}{ Organizational learning } & Managerial commitment & 0.559 & 0.0002 \\
& System perspective & 0.404 & 0.0004 \\
& Openness and experimentation & 0.621 & 0.0005 \\
& Knowledge transfer and integration & 0.532 & 0.0001 \\
& Total & 0.627 & 0.0003 \\
\hline
\end{tabular}

\section{Discussion}

Analyzing the new-fangled organizational learning in a new era, particularly in the area of the hospital and its impact on staff empowerment can play an important role in developing strategies to increase organizational efficiency and the human resource synergy. An organization to achieve superiority against other organizations should develop the intra-organizational customer's competencies and increase the amount of information and available knowledge. According to the fact that most research in the field of organizational learning is done in the context of industry and this concept is underestimated in health sector, therefore, this study is done as the relationship between organizational learning and staff empowerment at a hospital in Tehran University of 


\section{Medical Sciences.}

In the present study, organizational learning is analyzed in the form of four dimensions: managerial commitment, system perspective, openness and experimentation, knowledge transfer and integration. Based on the results of this study, a direct correlation was found between the dimensions of organizational learning and the staff empowerment component.

Among dimensions of organizational learning, the knowledge transfer and integration component had the highest average. Knowledge transfer and integration in a variety of internal knowledge, was gained in a staff basis and through conversation and interaction between people. It can be noted that nurses can discuss the strengths and weaknesses of their working environment and suggest the possible ideas and plans. The other three had a close average among them. In an openness and experimentation dimension it could be noted that the staff have a lack of general knowledge about the goals of the hospital and the amount of cooperation and relation for gaining the organizational objectives. In the area of managerial commitment it has to be mentioned that the managers should acknowledge the staff a means of an organizational asset and encourage them to participate in decision making and to encourage the ideas given by them and finally take staff learning as for granted. Also to note for upgrading the openness and experimentation dimension the managers have to know that this environment is a solution for achieving certain improvement in work processes, and the experience and ideas provided by external source supplies can perceived as an beneficial tool for the learning.

According to the study results, we have found a significant relationship between the system perspective and staff empowerment. By the extent of this relationship and for the acceleration of a system perspective in all the staff, the organization has to provide an infrastructure so that the organizational goals would be recognized as a set of valid, clear and operational and strategic plan, because the existence of a system perspective alone could lead to an increase in staff coordination and cooperation in goal achievement.

The Pearson correlation coefficient showed a significant relationship between other dimensions and the empowerment component. Efficiency and effectiveness between the two factors of knowledge transfer and integration and staff empowerment refer to ability of recognition, acquiring and use knowledge that lead to remove the internal knowledge barriers in an organization (Boudlaie, Koshkijahromi, \& Satarinasab, 2012; Yaghoubi, Agharahimi, Daryabeygi, \& Javadi, 2012). As a creative learning needs the openness and experimentation, it caused to focus on importance of both intra-organizational and extra-organizational ideas (Yaghoubi et al., 2012). The openness and experimentation like other components requires a culture that can promote innovation and creativity and it can improve staff entrepreneurship that leads to support innovative and creative ideas (Aghdasi \& Befruei, 2009).

Generally, the relationship between organizational learning and empowerment is examined in the main hypotheses; the results indicated a significant relationship between organizational learning and empowerment that is consistent with other studies (Boudlaie et al., 2012; Dastgerdi, Goudarzi, Asadi, \& Dastgerdi, 2010; Teymournejad \& Sarih Asfestani, 2010; Toolabi Rad, 2010). Therefore, achieving staff empowerment not only is an individuals or group effort that is achieved separately, but also macro factors such as the structure, policies, values, reward systems and organizational cultures should encourage and reinforce individual and group behavior in this regard. Creating, improving and reconstruction of these factors are possible by learning. Several studies have reported a closed correlation between these two components. In the study of public schools in United States of America, Bowen et al. mentioned the positive effect of implementation of organizational learning programs on empowering the schools (Bowen, Rose, \& Ware, 2006). Dastgerdi et al. (2010) also investigated the relationship between empowerment and organizational learning at Physical Education Organization of Iran that showed a significant and extreme relationship between these two factors. Teymournejad's study (2010) also showed that organizational learning is an affecting factor on psychological empowerment (sense of competence, self-organization, effectiveness, job meaningfulness and trust) can be considered as a basis for developing appropriate strategies for human resources in the field of organizational learning and psychological empowerment of staff, and organizations by using of it can rival to Competitors in the modern world that is constantly changing and continue with their lives.

\section{Limitations}

This study had some potential limitations that may affect the results such as studying only one hospital and a small sample as well as its limitation of results generalizability. Therefore, it is suggested that similar studies should be carried out on other public and also private hospital using large samples. The results of the present study were solely the result of a research and possibly more specialized investigation will show the more precise 
results. It is intended that the results of this research will help the administration sector of the hospitals to increase the level of the staff empowerment by creating an infrastructure for enhancing organizational learning.

\section{Conclusion}

The results of this study showed that managerial commitment, system perspective, openness and experimentation and knowledge transfer and integration components have a significant relationship with staff empowerment. Based on the results, there is a positive correlation between organizational learning and psychological empowerment that indicate a relatively strong correlation between these two variables and it Shows that, if the staff in the organization has higher levels of organizational learning they will be more effective in promoting psychological empowerment dimensions in the working process. Therefore, achieving staff empowerment not only is an individuals or group effort that is achieved separately, but also macro factors such as the structure, policies, values, reward systems and organizational cultures should encourage and reinforce individual and group behavior in this regard. Creating, improvement and reconstruction of these factors is possible by learning. Therefore, all organization should consider the formulation of a comprehensive management system to support organizational learning understanding the need for organizational learning, organizing a basis creation of systematic thinking, emphasize on the staff competency, a motion to change the mental models of staff as organizational assets, special attention to the research area, design and implementation of a knowledge management system, and provide mechanisms for applying intra-organizational and extra-organizational successful experiences in order to promote organizational learning component.

\section{Acknowledgments}

The Authors would like to thank all participants for their kind cooperation with the researchers in collecting the data.

\section{References}

Abeysekera, I. (2006). The project of intellectual capital disclosure: Researching the research. Journal of Intellectual Capital, 7(1), 61-77. http://dx.doi.org/10.1108/14691930610639778

Aghdasi, M., \& Befruei, M. K. (2009). Comparative Study of organizational learning capabilities as an organizational source of knowledge in public and private hospitals of Tehran: Nurses Perspectives. Iran Journal of Nursing, 21(56), 69-79.

Bahramian, M. R. (2005). Study areas and administrative terms for realization of total quality management. M.Sc Thesis, Khorasgan University, Isfahan.

Boudlaie, H., Koshkijahromi, A., \& Satarinasab, R. (2012). Organizational Learning and Trust, Moderating Rings between Psychological Empowerment and Organizational Commitment. Quarterly Journal of Management and Development Process, 24(1), 67-93.

Bowen, G. L., Rose, R. A., \& Ware, W. B. (2006). The reliability and validity of the School Success Profile Learning Organization measure. Evaluation and Program Planning, 29(1), 97-104. http://dx.doi.org/10. 1016/j.evalprogplan.2005.08.005

Dastgerdi, K., Goudarzi, M., Asadi, H., \& Dastgerdi, M. (2010). To Determine the Relationship between Employees' Empowerment and Organizational Learning in Physical Education Organization. Journal of Sport Management, 2(7), 111-124.

Gagné, M., \& Deci, E. L. (2005). Self-determination theory and work motivation. Journal of Organizational behavior, 26(4), 331-362. http://dx.doi.org/10.1002/job.322

García-Morales, V. J., Lloréns-Montes, F. J., \& Verdú-Jover, A. J. (2007). Influence of personal mastery on organizational performance through organizational learning and innovation in large firms and SMEs. Technovation, 27(9), 547-568. http://dx.doi.org/10.1016/j.technovation.2007.02.013

Holsapple, C. (2003). Handbook on knowledge management 2: Knowledge directions (Vol. 2). Springer. http://dx. doi.org/10.1007/978-3-540-24748-7

Hornstein, H. A. (2006). Empowerment as a Way to Facilitate Change: Can Process Consultation Help? $O D$ PRACTITIONER, 38(1), 4.

Jerez-Gomez, P., Céspedes-Lorente, J., \& Valle-Cabrera, R. (2005). Organizational learning capability: A proposal of measurement. Journal of Business Research, 58(6), 715-725. http://dx.doi.org/10.1016/j.jbusres. 2003.11.002

Marquardt, M. J. (1996). Building the learning organization. Translator: Zali MR. Tehran: University 
Publications: McGraw-Hill New York.

Nasr Esfehani, A. (2007). Empowerment Mystery. Journal of Management and Development Planning.

Nikbakht, A., Siadat, S. A., Hoveida, R., \& Moghadam, A. (2010). Study of the Relationship between Knowledge Management and Chairpersons Leadership Styles at Isfahan University of Medical Sciences from Faculty View Points. Health Information Management, 7(2), 216-224.

Otala, L. (2000). Oppimisen etu: Kilpailukykyä muutoksessa (3. uud. painos). Porvoo: WSOY.

Paajanen, P. (2012). Managing and Leading Organizational Learning and Knowledge Creation. Tampereen teknillinen yliopisto. Julkaisu-Tampere University of Technology. Publication; 1062.

Teymournejad, K., \& Sarih Asfestani, R. (2010). Effects of Organizational Learning on Psychological Empowement in the Ministry of Economic Affairs and Finance. Journal of Management Studies in Development, 20(62), 37-59.

Toolabi Rad, H. (2010). A Survey of Relationship Between Organizational Learning And Staff Empowerment In Imam Khomeini Hospital of Kohdasht. M.Sc Thesis, Iran University of Medical Sciences, Tehran.

Yaghoubi, M., Agharahimi, Z., Daryabeygi, M., \& Javadi, M. (2012). The Relationship between Application of Organizational Learning and Demographic Features of Staffs Working in Pediatrics Medical Center. Iranian Journal of Medical Education, 11(9), 1074-1082.

Zhang, L., Tian, Y., \& Qi, Z. (2006). A conceptual model of organizational learning based on knowledge sharing. Paper presented at the Advanced Learning Technologies, 2006. Sixth International Conference on.

\section{Copyrights}

Copyright for this article is retained by the author(s), with first publication rights granted to the journal.

This is an open-access article distributed under the terms and conditions of the Creative Commons Attribution license (http://creativecommons.org/licenses/by/3.0/). 